\title{
Desempenho e qualidade dos ovos de poedeiras comerciais alimentadas com rações contendo diferentes níveis de metionina e lisina ${ }^{1}$
}

\author{
Mayra Fernanda Rizzo Silva ${ }^{2}$, Douglas Emygdio de Faria ${ }^{3}$, Paula Wick Rizzoli ${ }^{2}$, Andréa \\ Luciana dos Santos ${ }^{4}$, Márcia Izumi Sakamoto${ }^{2}$, Henrique Rosa Baltazar de Souza ${ }^{2}$
}

\footnotetext{
1 Projeto financiado pela CAPES.

2 Programa de pós-graduação em Zootecnia, FZEA - USP.

${ }^{3}$ Departamento de Zootecnia, FZEA-USP, Pirassununga, SP.

4 Universidade Federal de Mato Grosso.
}

\begin{abstract}
RESUMO - Foram avaliados os efeitos dos níveis de metionina e lisina sobre o desempenho e a qualidade interna e externa dos ovos de poedeiras comerciais. Foram utilizadas 256 poedeiras Hisex White com 68 semanas de idade, alojadas individualmente em delineamento inteiramente casualizado em arranjo fatorial $4 \times 4$, com quatro níveis de lisina $(0,482 ; 0,682 ; 0,882$ e $1,082 \%)$ e metionina $(0,225 ; 0,318 ; 0,411$ e $0,505 \%)$, totalizando 16 dietas, cada uma com quatro repetições de quatro aves. O desempenho foi avaliado por meio das características consumos de ração, lisina, metionina, proteína bruta e de energia, peso, produção e massa de ovos e conversão alimentar. A qualidade interna dos ovos foi avaliada por meio das características peso e porcentagem de albúmen e gema e pela unidade Haugh. As aves apresentaram máxima produção de ovos quando alimentadas com rações contendo 0,444\% de metionina total e 0,872\% de lisina total. A classificação dos ovos por tipo e as características de qualidade interna e externa dos ovos não foram influenciadas pelos níveis de metionia e lisina da dieta.
\end{abstract}

Palavras-chave: aminoácidos, exigências nutricionais, galinhas, ovos

\section{Performance and egg quality of commercial laying hens fed diets with different levels of methionine and lysine}

\begin{abstract}
This experiment was carried out to evaluate the effects of levels of methionine and lysine on performance and on the internal and external egg quality of commercial laying hens. It was used 256 Hisex White laying hens at 68 weeks of age, which were individually housed in a complete random design in a $4 \times 4$ factorial scheme with four levels of lysine $(0.482,0.682,0.882$, and $1.082 \%)$ and of methionine $(0.225,0.318,0.411$, and $0.505 \%)$ totaling sixteen diets with four replicates with four birds each. Performance was evaluated through the following characteristics: feed intake, consumption of lysine, methionine, crude protein and energy, weight, production and mass of eggs and feed conversion. Internal quality of eggs was evaluated through the characteristics of weight and yolk percentage and by Haugh unit. Birds showed maximal egg production when fed rations with $0.444 \%$ of total methionine and $0.872 \%$ total lysine. Rating of eggs by their types and internal and external quality of eggs were not influenced by levels of methionine and lysine in the diet.
\end{abstract}

Key Words: amino acids, egg, hens, nutritional requirements

\section{Introdução}

Durante muito tempo, as formulações de rações para aves foram baseadas no conceito de proteína bruta, o que resultava em dietas com conteúdo de aminoácidos acima do exigido pelos animais. Hoje são conhecidos os requerimentos de aminoácidos essenciais para cada fase da postura, mas em razão das constantes mudanças que ocorrem na genética, manejo, ambiência e sanidade, existe a necessidade constante de atualização das exigências nutricionais das aves.
Metionina e lisina são, nesta ordem, os primeiros aminoácidos limitantes, em rações à base de milho e farelo de soja, fornecidas às poedeiras. Estudos envolvendo a suplementação destes aminoácidos mostram resultados positivos no desempenho das aves e na qualidade dos ovos, mas os níveis recomendados variam conforme a fonte consultada e o parâmetro de produção escolhido para estabelecer o requerimento.

O NRC (1994) recomenda $690 \mathrm{mg} / \mathrm{ave} / \mathrm{dia}$ de lisina total e $300 \mathrm{mg} /$ ave/dia de metionina total para maximizar a massa 
de ovos de poedeiras leves que consomem $100 \mathrm{~g}$ de ração com 15\% de PB. De acordo com Rostagno et al. (2005), poedeiras leves com $1650 \mathrm{~g}$ necessitam de $745 \mathrm{mg}$ de lisina e $365 \mathrm{mg}$ de metionina/ave/dia totais. Novak \& Scheideler (1998) e Scheideler et al. (1996) recomendaram um consumo diário de 850 a 900mg para otimização da massa de ovos, conversão alimentar e produção de ovos. Schutte \& Smink (1998) verificaram melhor conversão alimentar com massa de ovos de $57 \mathrm{~g} / \mathrm{ave} /$ dia quando poedeiras leves de 24 a 36 semanas ingeriram $900 \mathrm{mg}$ de lisina total/ave/dia. De acordo com Cupertino et al. (2009), as exigências de lisina digestível para poedeiras leves e semipesadas para aumentar a massa de ovo no período de 54 a 70 semanas de idade são de 784 e 748 mg de lisina digestível/ave/dia, respectivamente.

Os objetivos neste trabalho foram determinar os melhores níveis de lisina e metionina e avaliar seus efeitos sobre as características de desempenho e qualidade dos ovos em poedeiras brancas com 68 semanas de idade.

\section{Material e Métodos}

Foram utilizadas 256 poedeiras da linhagem Hisex White com 68 semanas de idade, alojadas individualmente em gaiolas metálicas medindo 0,25 m de largura, 0,40 m de altura e $0,45 \mathrm{~m}$ de profundidade por um período total de oito semanas, considerando as duas primeiras semanas de adaptação. Utilizou-se delineamento experimental inteiramente casualizado em arranjo fatorial $4 \times 4$, com quatro níveis de lisina $(0,482 ; 0,682 ; 0,882$ e $1,082 \%)$ e quatro de metionina $(0,225 ; 0,318 ; 0,411$ e $0,505 \%)$, totalizando 16 dietas, cada uma avaliada com quatro repetições de quatro aves.

As temperaturas e umidade máximas e mínimas durante o período experimental foram de 29,4 e $19,9^{\circ} \mathrm{C}$ e 68 e $32 \%$, respectivamente. As aves receberam um total de 17 horas diárias de luz sendo o alimento e a água fornecidos à vontade.

As dietas foram formuladas após análise de matéria seca e proteína bruta, metodologia descrita por Silva (1998), e análise de aminoácidos, pela técnica de High Performance Liquid Chromatography, descrita pela Association of Official Analytical Chemistries International (AOAC, 1994), dos principais ingredientes utilizados milho e farelo de soja (Tabela 1). Por segurança e precisão experimental, as rações experimentais também foram analisadas (Tabela 2). As dietas foram isocalóricas e isossódicas e o teor proteico das cinco primeiras dietas foi inferior aos das demais, atendendo, no entanto, às exigências de aminoácidos.
Foram avaliadas as características de desempenho, como consumo de ração (g/ave/dia), consumo de proteína bruta (g/ave/dia), consumo de lisina (g/ave/dia), consumo de energia metabolizável (kcal/ave/dia), produção de ovos (\% ovos/ave/dia), peso de ovos (g), massa de ovos (g/ave/dia) e conversão alimentar (g ração/g ovo). As características de qualidade interna do ovo, unidade Haugh e porcentagens de gema e albúmen e a qualidade externa, a porcentagem e espessura de casca foram avaliadas utilizando-se dois ovos por parcela experimental em dois dias da semana. Na terceira e sexta semana experimental, todos os ovos das parcelas experimentais foram pesados em um dia da semana para classificação segundo os intervalos de peso: médio (50 a 55 g), grande (55 a 60 g), extra (60 a 65 g) e jumbo (> 65 g), de acordo com MAPA (2006).

Os dados experimentais foram analisados utilizando-se o pacote estatístico SAS ${ }^{\circledR}$ (1998) e submetidos ao teste de uniformidade das variâncias para análise de variância. A análise de regressão foi aplicada apenas para dados que proporcionaram efeito significativo de níveis de metionina e lisina e interação entre os dois fatores. Para as análises da classificação dos ovos por tipo, foi necessário utilizar o teste não-paramétrico de Kruskal-Wallis, a 5\% de significância, uma vez que a distribuição dos dados não apresentou comportamento normal.

Tabela 1 - Teores de matéria seca, proteína bruta e aminoácidos dos ingredientes (g/100 g do produto na matéria natural)

\begin{tabular}{lcc}
\hline & Milho & Farelo de soja \\
\hline Matéria seca & 91,56 & 90,52 \\
Proteína bruta & 8,94 & 47,40 \\
Lisina & 0,254 & 2,944 \\
Treonina & 0,321 & 1,800 \\
Metionina & 0,199 & 0,626 \\
Cistina & 0,200 & 0,662 \\
Metionina+cistina & 0,399 & 1,286 \\
Alanina & 0,613 & 2,073 \\
Arginina & 0,422 & 3,507 \\
Ácido aspártico & 0,583 & 5,389 \\
Ácido glutâmico & 1,519 & 3,532 \\
Glicina & 0,344 & 2,126 \\
Histidina & 0,249 & 1,239 \\
Isoleucina & 0,291 & 2,108 \\
Leucina & 0,972 & 3,722 \\
Fenilalanina & 0,407 & 2,401 \\
Serina & 0,422 & 2,445 \\
Tirosina & 0,332 & 1,653 \\
Valina & 0,387 & 2,268 \\
Triptofano ${ }^{1}$ & 0,060 & 0,660 \\
\hline 1 Segundo Rostagno & &
\end{tabular}

${ }^{1}$ Segundo Rostagno et al. (2000). 


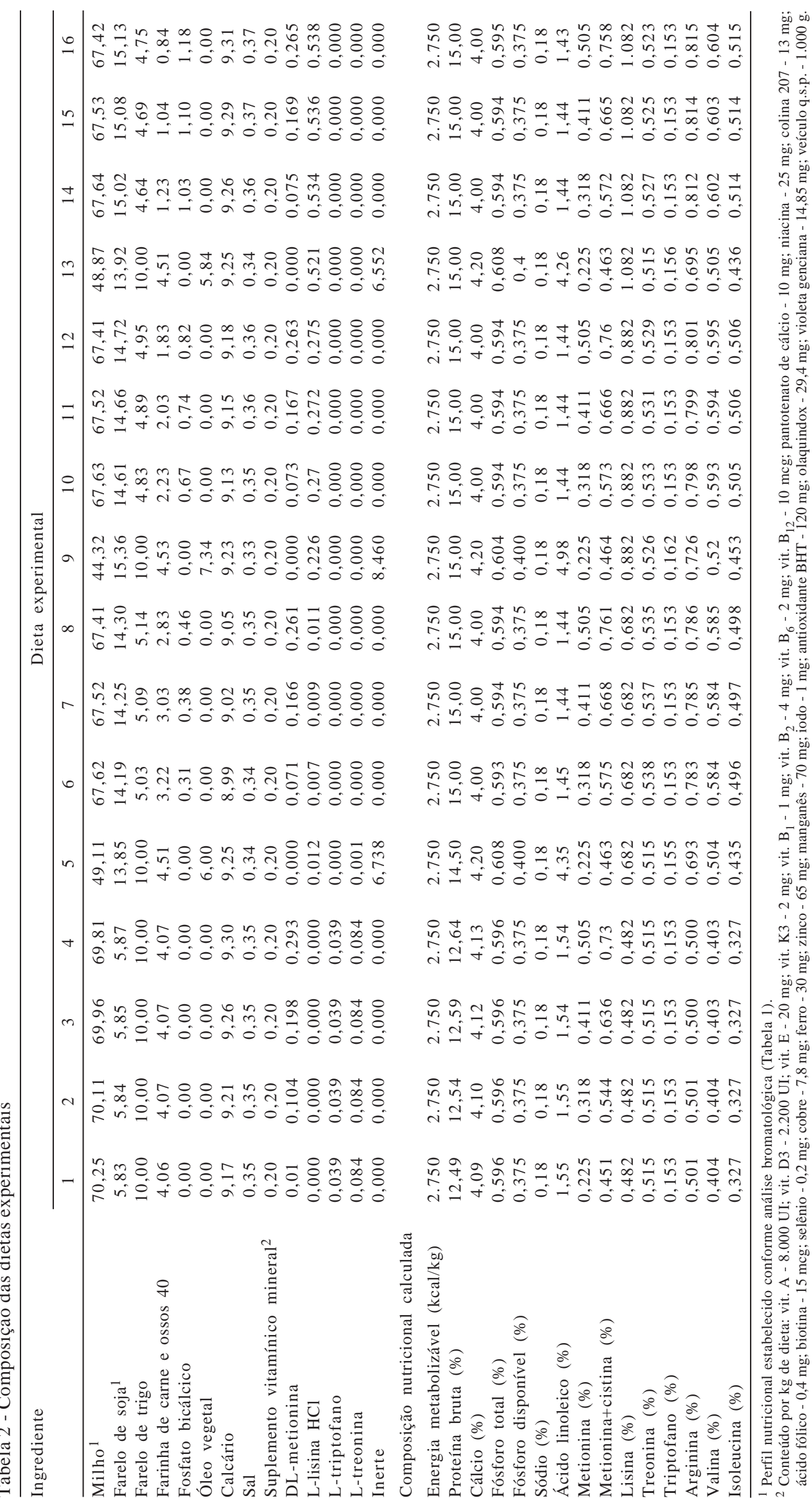




\section{Resultados e Discussão}

Os níveis de metionina e lisina tiveram efeito quadrático sobre o consumo de ração, com níveis máximos estimados em 0,456 e 0,874\%, respectivamente (Tabelas 3, 4 e 5). Esses resultados divergem dos encontrados por Goulart (1997) e Sá et al. (2007), que não verificaram efeito dos níveis de lisina da ração no consumo de ração.

$\mathrm{O}$ consumo de metionina aumentou de forma linear crescente de acordo com os níveis de metionina da ração (Tabela 4$)$ e de forma quadrática $(\mathrm{P}<0,05)$ conforme os níveis de lisina, apresentando melhores resultados no nível máximo estimado em 0,866\% (Tabela 5). Somente para o consumo de lisina houve interação entre os fatores estudados. Nos níveis de 0,682; 0,882 e 1,082\% de lisina, os níveis de 0,430; 0,511 e $0,440 \%$ demetionina, respectivamente, proporcionaram o maior consumo de lisina (Tabela 6). O nível de $0,482 \%$ de lisina não promoveu diferença significativa $(\mathrm{P}>0,05)$ nessa variável.

O consumo de energia metabolizável apresentou resposta quadrática $(\mathrm{P}<0,05)$ aos níveis de metionina e lisina estudados, de modo que os níveis para máximo consumo de energia foram estimados em 0,456 e 0,874\%, respectivamente (Tabelas 4 e 5).

A produção de ovos também respondeu de forma quadrática $(\mathrm{P}<0,05)$ aos níveis de metionina e lisina estudados, que foram estimados em 0,444 e $0,872 \%$, respectivamente, para máxima produção (Tabelas 4 e 5).

Os níveis de metionina tiveram efeito linear crescente sobre o peso de ovos (Tabela 4). Koelkebeck et al. (1991) estudaram adição de 1\% de aminoácidos em excesso (lisina, metionina, treonina ou triptofano) e observaram maior peso dos ovos nas aves alimentadas com a dieta suplementada com metionina. Shafer et al. (1996) avaliaram a ingestão de 326 e $512 \mathrm{mg} /$ ave/dia de metionina e notaram maior peso dos ovos, massa de ovos e sólidos totais quando utilizaram o mais alto nível do aminoácido.

Efeito quadrático dos níveis de metionina e lisina foi observado para a massa de ovos $(\mathrm{P}<0,05)$, que foi maior nos níveis de 0,458 e 0,884\% desses aminoácidos (Tabelas 4 e 5). Cupertino et al. (2009) verificaram que 0,724 e 0,692\% de lisina digestível na dieta para poedeiras leves e semipesadas, respectivamente, otimiza a massa de ovo no período de 54 a 70 semanas de idade.

A conversão alimentar apresentou resposta quadrática aos níveis de metionina estudados $(\mathrm{P}<0,05)$ e foi melhor no nível estimado de $0,442 \%$ (Tabela 4). Os níveis de lisina não influenciaram esse parâmetro (Tabela 5), o que contraria os resultados encontrados por Goulart (1997) e Sá et al. (2007), que verificaram efeito quadrático.

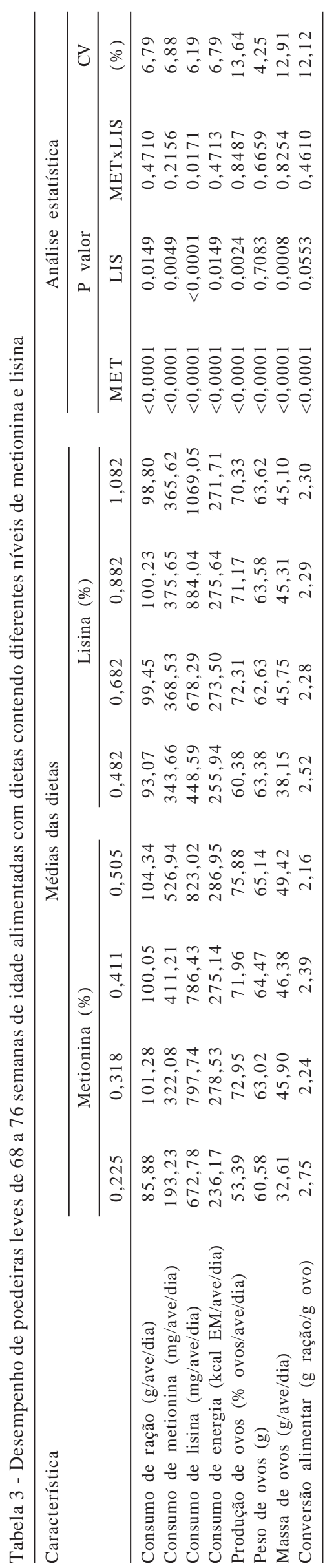

R. Bras. Zootec., v.39, n.10, p.2246-2252, 2010 
Considerando todos os valores de metionina e lisina estimados para as características avaliadas, tem-se como valores médios os níveis de $0,450 \%$ de metionina e $0,870 \%$ de lisina, que correspondem ao consumo diário de $468 \mathrm{mg}$ e $876 \mathrm{mg} / \mathrm{ave} / \mathrm{dia}$, respectivamente. Para todas as características avaliadas, a variação obtida ocorreu na segunda casa decimal (Tabelas 4 e 5). Esses valores são superiores aos recomendados pelo NRC (1994), que recomenda $300 \mathrm{mg}$ de metionina e $690 \mathrm{mg}$ de lisina por ave/dia para poedeiras leves consumindo $100 \mathrm{~g}$ de ração com 15\% de PB, e por Rostagno et al. (2005), de 365 mg de metionina total e $745 \mathrm{mg}$ de lisina total por ave/dia para poedeiras leves com $1.650 \mathrm{~g}$.

Bertechini et al. (1995) sugeriram consumo diário de $789 \mathrm{mg}$ de lisina/ave para otimizar a produção de ovos e conversão alimentar, enquanto Schutte \& Smink (1998) verificaram melhor conversão alimentar com massa de ovos de $57 \mathrm{~g} /$ ave/dia em poedeiras leves de 24 semanas ingerindo $900 \mathrm{mg}$ de lisina total/ave/dia.

Shafer et al. (1996) observaram maior peso dos ovos e massa de ovos quando forneceram $512 \mathrm{mg}$ de metionina/ave/dia (experimento 1). No mesmo estudo, porém no segundo experimento, forneceram níveis intermediários (328; 354; 392 e 423mg/ave/dia) e não notaram diferença na produção e no peso dos ovos entre os níveis testados.

Prochaska et al. (1996), trabalhando com níveis de lisina variando de 667 a $1.613 \mathrm{mg} /$ ave/dia, observaram que a maior ingestão de lisina proporcionou aumento no peso do ovo, no peso do albúmen e na quantidade de sólidos totais e proteína no albúmen (experimento 1). No mesmo estudo, (experimento 2), com níveis mais próximos de ingestão de lisina (638 a $1.165 \mathrm{mg} /$ ave/dia), esses autores observaram que a ingestão de $828 \mathrm{mg} /$ ave/dia melhorou a produção de ovos e o peso de albúmen e gema.

A classificação dos ovos não foi influenciada pelos níveis de metionina e lisina (Tabela 7). Apesar de o peso dos ovos ter sido afetado pelos níveis de metionina, não foi suficiente para mudar de faixa de peso pré-estabelecida.

Não houve efeito significativo dos níveis de lisina e metionina sobre as características de qualidade interna e externa dos ovos (Tabela 8). Esses resultados diferem dos encontrados por Shafer et al. (1998), que estudaram altos

Tabela 4 - Equações de regressão das características de desempenho de poedeiras leves de 68 a 76 semanas de idade alimentadas com dietas com diferentes níveis de metionina

\begin{tabular}{lccc}
\hline Característica & Equação de regressão & $\begin{array}{c}\text { Ponto de máxima/ } \\
\text { Ponto de mínima }\end{array}$ & $\begin{array}{c}\text { Exigência de } \\
\text { metionina }\end{array}$ \\
\hline Consumo de ração (g/ave/dia) & $\mathrm{Y}=37,667+291,06 \mathrm{X}-319,21 \mathrm{X}^{2}$ & 104,02 & 0,456 \\
Consumo de metionina (mg/ave/dia) & $\mathrm{Y}=-62,908+1168,7 \mathrm{X}$ & - & 0,88 \\
Consumo de energia (kcal EM/ave/dia) & $\mathrm{Y}=103,58+800,39 \mathrm{X}-877,76 \mathrm{X}^{2}$ & 286,04 & 0,99 \\
Produção de ovos (\% ovos/ave/dia) & $\mathrm{Y}=-12,522+399,91 \mathrm{X}-450,2 \mathrm{X}^{2}$ & 76,29 & 0,456 \\
Peso do ovo (g) & $\mathrm{Y}=57,391+16,206 \mathrm{X}$ & - & 0,444 \\
Massa de ovos (g/ave/dia) & $\mathrm{Y}=-12,384+269,73 \mathrm{X}-294,76 \mathrm{X}^{2}$ & 49,32 & - \\
Conversão alimentar & $\mathrm{Y}=4,5511-10,917 \mathrm{X}+12,357 \mathrm{X}^{2}$ & 2,14 & 0,90 \\
& & & 0,94 \\
\end{tabular}

Tabela 5 - Equações de regressão das características de desempenho de poedeiras leves de 68 a 76 semanas de idade alimentadas com dietas formuladas com diferentes níveis de lisina

\begin{tabular}{|c|c|c|c|c|}
\hline Característica & Equação de regressão & $\begin{array}{l}\text { Ponto de } \\
\text { máxima }\end{array}$ & $\begin{array}{l}\text { Exigência } \\
\text { lisina (\%) }\end{array}$ & $\mathrm{R}^{2}$ \\
\hline Consumo de ração (g/ave/dia) & $Y=63,452+85,328 X-48,813 X^{2}$ & 100,74 & 0,874 & 0,982 \\
\hline Consumo de metionina (mg/ave/dia) & $Y=212,75+376,57 X-217,5 X^{2}$ & 375,74 & 0,866 & 1,000 \\
\hline Consumo de energia (kcal EM/ave/dia) & $Y=174,44+234,79 X-134,31 X^{2}$ & 277,05 & 0,874 & 0,982 \\
\hline Produção de ovos (\% ovos/ave/dia) & $Y=12,505+139,18 X-79,812 X^{2}$ & 73,18 & 0,872 & 0,902 \\
\hline Massa de ovos (g/ave/dia) & $Y=7,9291+87,375 X-49,438 X^{2}$ & 46,53 & 0,884 & 0,915 \\
\hline
\end{tabular}

Tabela 6 - Equações de regressão do desdobramento da interação entre lisina e metionina para o consumo de lisina em poedeiras alimentadas com dietas formuladas com diferentes níveis de metionina e lisina

\begin{tabular}{|c|c|c|c|c|c|}
\hline Característica & $\begin{array}{l}\text { Nível de } \\
\text { lisina (\%) }\end{array}$ & Equação de regressão & $\begin{array}{l}\text { Ponto de } \\
\text { máxima }\end{array}$ & $\begin{array}{c}\text { Exigência } \\
\text { metionina (\%) }\end{array}$ & $\mathrm{R}^{2}$ \\
\hline \multirow{4}{*}{$\begin{array}{l}\text { Consumo de lisina } \\
\text { (mg/ave/dia) }\end{array}$} & 0,482 & Ns & - & - & - \\
\hline & 0,682 & $Y=207,04+2386,3 X-2773,3 X^{2}$ & 720,37 & 0,430 & 0,987 \\
\hline & 0,882 & $Y=245,61+2850,6 X-2788,5 X^{2}$ & 974,13 & 0,511 & 0,938 \\
\hline & 1,082 & $Y=454,3+3055,1 X-3471,3 X^{2}$ & 1126,5 & 0,440 & 0,695 \\
\hline
\end{tabular}

ns - não-significativo. 

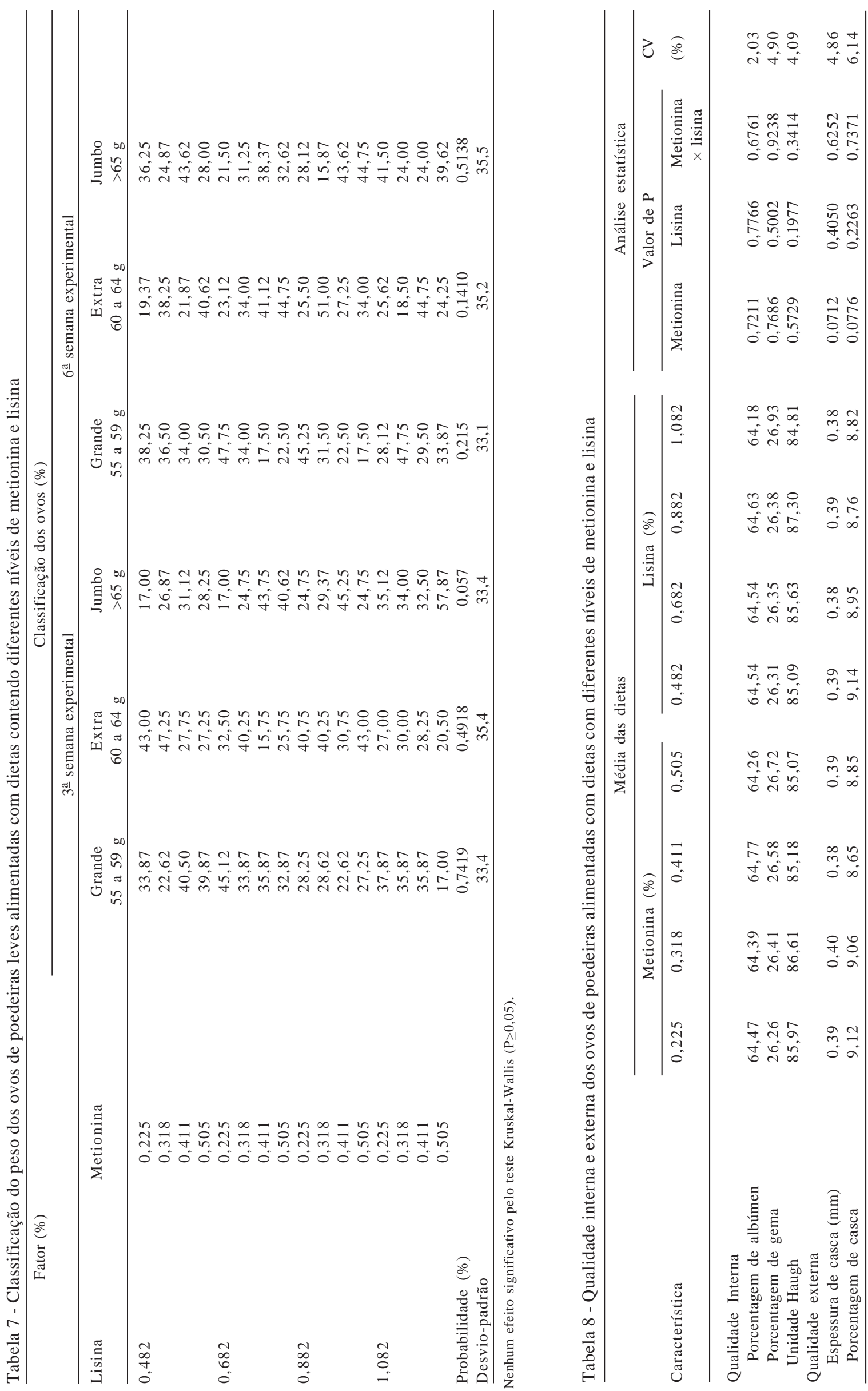

R. Bras. Zootec., v.39, n.10, p.2246-2252, 2010 
níveis de ingestão de metionina (413; 507 e 556 mg/ave/dia) e observaram aumento na porcentagem de albúmen com os níveis de 507 e 556 mg/ave/dia e na porcentagem de gema com $556 \mathrm{mg} /$ ave/dia. Neste estudo, o nível mais alto de metionina (527 mg/ave/dia) não foi suficiente para alterar as porcentagens de albúmen e gema.

Novak et al. (2004) elevaram os níveis de lisina em dois períodos: de 860 para $959 \mathrm{mg} / \mathrm{ave} / \mathrm{dia}$ (20 a 43 semanas de idade) e de 715 para $816 \mathrm{mg} / \mathrm{ave} / \mathrm{dia}$ (44 a 63 semanas) e verificaram aumento na porcentagem de albúmen, resultado não detectado neste estudo mesmo com a ampla faixa de lisina utilizada (449 a 1069 mg/ave/dia). No entanto, nenhum efeito foi verificado nos valores de unidade Haugh, fato ocorrido também neste experimento.

\section{Conclusões}

A exigência de metionina total e de lisina total para máxima produção de ovos foi estimada em 0,444 e 0,872\%, respectivamente. Os níveis de metionina e lisina não influenciaram a classificação dos ovos por tipo nem as características que expressam a qualidade interna e externa dos ovos. Considerando os valores estimados, recomendam-se níveis médios de $0,450 \%$ (correspondente a 468 mg/ave/dia) de metionina total e $0,870 \%$ (correspondente a $876 \mathrm{mg} /$ ave/dia) de lisina total em dietas para poedeiras para máximos consumos de ração, de metionina e energia e máxima produção, peso e massa de ovos.

\section{Referências}

ASSOCIATION OF OFFICIAL ANALYTICAL CHEMISTRY AOAC. Official methods of analysis. 16.ed. Arlington: AOAC International, 1995. 1025p.

BERTECHINI, A.G.; TEIXEIRA, A.S.; LIRA, V.M.C. Níveis de lisina para poedeiras comerciais leves na fase de pico de postura. In: CONFERÊNCIA APINCO DE CIÊNCIA E TECNOLOGIA AVÍCOLA, 1995, Curitiba. Anais... Curitiba: Fundação APINCO de Ciência e Tecnologia Avícola, 1995. p.75.

CUPERTINO, E.S.; GOMES, P.C.; ALBINO, L.F.T. et al. Exigência nutricional de lisina digestível para galinhas poedeiras de 54 a
70 semanas de idade. Revista Brasileira de Zootecnia, v.38, n.3, p.480-487, 2009.

GOULART, C.C. Exigência nutricional de lisina para poedeiras leves e semipesadas. 1997. 51f. Dissertação (Mestrado em Zootecnia) - Universidade Federal de Viçosa, Viçosa, MG.

KOELKEBECK, K.W.; BAKER, D.H.; HAN, Y. et al. Effect of excess lysine methionine, threonine or tryptophan on production performance of laying hens. Poultry Science, v.70, p.1651-1653, 1991.

MINISTÉRIO DA AGRICULTURA PECUÁRIA E ABASTECIMENTO - MAPA. Disponível em: <www.agricultura.gov.br>. Acesso em: 20/6/2006.

NATIONAL RESEARCH COUNCIL - NRC. Nutrient requirements of poultry. 9.ed. Washington, DC: National Academy Press, 1994. 156p.

NOVAK, C.L.; SCHEIDELER, S.C. The combined effects of lysine and TSAA in two strains of laying hens. Poultry Science, v.77 (Suppl. 1), p.102 (Abstr.), 1998.

NOVAK, C.; YAKULT, H.; SCHEIDELER, S.E. The combined effects of dietary lysine and total sulfur amino acid level on egg production parameters and egg components in Dekalb Delta laying hens. Poultry Science, v.83, p.977-984, 2004.

PROCHASKA, J.F.; CAREY, J.B.; SHAFER, D.J. The effect of L-lysine intake on egg component yield and composition in laying hens. Poultry Science, v.75, p.1268-1277, 1996.

ROSTAGNO, H.S., ALBINO, L.F.T., DONZELE, J.L. et al. Tabelas brasileiras para aves e suínos: Composição de alimentos e exigências nutricionais. Viçosa, MG: UFV, 2000. 141p.

ROSTAGNO, H.S.; ALBINO, L.F.T.; DONZELE, J.L. et al, Tabelas brasileiras para aves e suínos: Composição de alimentos e exigências nutricionais. 2.ed. Viçosa, MG: UFV, 2005. 186p.

SÁ, L.M.; GOMES, P.C.; CECON, P.R. et al. Exigência nutricional de lisina digestível para galinhas poedeiras no período de 34 a 50 semanas de idade. Revista Brasileira de Zootecnia, v.36, p.1846-1853, 2007.

SCHEIDELER, S.E.; NOVAK, C.; SELL, J.L. et al. Hisex White Leghorn lysine requirement for optimum body weight and egg production during early lay. Poultry Science, v.75 (Suppl.1), p.86. (Abstr.), 1996.

SCHUTTE, J.B.; SMINK, W. Requeriment of laying hen for apparent fecal digestible lysine. Poultry Science, v.77, p.697-701, 1998.

SILVA, D.J. Análise de alimentos: métodos químicos e biológicos. Viçosa, MG: UFV, 1998. 166p.

SHAFER, D.J.; CAREY, J.B.; PROCHASKA, J.F. Effect of dietary methionine intake on egg component yield and composition. Poultry Science, v.75, p.1080-1085, 1996.

SHAFER, D.J.; CAREY, J.B.; PROCHASKA, J.F. et al. Dietary methionine effects on egg component yield, composition, functionality and texture profile analysis. Poultry Science, v.7, p.1056-1062, 1998.

STATISTICAL ANALYSIS SYSTEM - SAS. User's guide, version 6.12, 4.ed. v.2, Cary: 1998. 842p. 